\title{
Acute fibrinous and organizing pneumonia associated with influenza A/H1N1 pneumonia after lung transplantation
}

\author{
Claudia Otto ${ }^{1}$, Daniela Huzly ${ }^{2}$, Lars Kemna ${ }^{3}$, Annegret Hüttel ${ }^{4}$, Christoph Benk $^{5}$, Siegbert Rieg ${ }^{6}$, Till Ploenes ${ }^{7}$, \\ Martin Werner ${ }^{1}$ and Gian Kayser ${ }^{1 *}$
}

\begin{abstract}
Background: Immunocompromised patients, particularly after lung transplantation, are at high risk to develop atypical forms of pulmonary infections including influenza A/H1N1. Acute Fibrinous and Organizing Pneumonia (AFOP) is a special histological pattern in acute respiratory failure with high mortality.

Case presentation: We describe a 66-year-old woman with double lung transplantation in August 2009 due to end stage pulmonary fibrosis. After prolonged weaning and subsequent promising course, she developed atypical pneumonia with diffuse pulmonary infiltrates in both lungs in January 2010. Infection with influenza A/H1N1 virus was verified. The patient rapidly suffered from respiratory insufficiency and died eight days after this diagnosis. The post-mortem revealed especially in the lower parts of the lungs the classical histological pattern of pure AFOP. Molecular analyses of lung tissue were positive for influenza A/H1N1.

Conclusion: To our knowledge we present the first case of AFOP triggered by viral infection, here proven to be influenza virus A/H1N1. Thus, also in the setting of viral infection the highly deadly differential diagnosis of AFOP must be considered.
\end{abstract}

Keywords: AFOP, Influenza A/H1N1, Acute lung failure, Lung transplantation, Viral infection

\section{Background}

Immunocompromised patients, especially after lung transplantation are at high risk to develop atypical pneumonias. Among viral infections, influenza A/H1N1 pneumonia can lead to severe respiratory conditions in this patient group often resulting in deadly respiratory insufficiency. Acute fibrinous and organizing pneumonia (AFOP) is a distinct reaction pattern in acute respiratory failure with high mortality rate of upto $90 \%$. Although some causes of AFOP are known so far, its pure form without the presence of accompanying hyaline membranes typical for diffuse alveolar damage (DAD) has not been described to be linked to viral pneumonias.

\footnotetext{
* Correspondence: gian.kayser@uniklinik-freiburg.de

${ }^{1}$ Institute of Pathology, University Medical Center Freiburg, Breisacher Strasse 115a, D-79106, Freiburg, Germany

Full list of author information is available at the end of the article
}

\section{Case presentation}

\section{Clinical course}

The 66-year old caucasian female patient suffered from end-stage pulmonary fibrosis caused by usual interstitial pneumonia (UIP) first diagnosed in November 2004. According to the guidelines of the International Society for Heart and Lung Transplantation, the patient was submitted to double sided lung transplantation in August 2009. Immediate post-operative course was complicated by prolonged respiratory weaning with the necessity of percutaneous tracheotomy. The patient could not be immunized with influenza vaccination due to poor general condition in September and October 2009, the vaccination period for the seasonally expected influenza viruses. In November 2009, the patient was transferred to rehabilitation treatment. During the end of December 2009 and the beginning of January 2010, she complained about persistent cough. Because of aggravation of her general and especially respiratory condition, she was admitted to a local

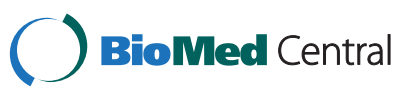


Table 1 Timeline of the clinical course

\begin{tabular}{lll}
\hline Date & Clinical course & Therapy \\
\hline $\begin{array}{l}\text { November } 2004 \\
\text { August } 2009\end{array}$ & Diagnosis of usual interstitial pneumonia (UIP) & $\begin{array}{l}\text { Double lung transplantation, } \\
\text { complicated postoperative course }\end{array}$ \\
$\begin{array}{l}\text { November 2009 } \\
\text { December 2009 - } \\
\text { January 2010 }\end{array}$ & Rehabilitation treatment & Admission to general hospital \\
3.1.2010 & Aggravation of general/ respiratory condition & Admission to intensive care unit \\
& Respiratory insufficiency & Intubation \\
5.1.2010 & Nasotracheal secretion positive for viral influenza A/H1N1 RNA (working diagnosis: & Meropenem, clarithromycin and \\
7.1.2010 & Detection of viral influenza A/H1N1 RNA by real-time PCR (bronchoscopy) & Oseltamir \\
& Detection of mutation causing resistence against Oseltamivir & Switch from oseltamivir to zanamivir \\
& Acute renal failure & Continuous venous-venous \\
& Respiratory insufficiency & hemofiltration \\
8.1.2010 & Rapidly progressive respiratory failure & $\begin{array}{l}\text { Extracorporeal interventional lung assist } \\
\text { implantation }\end{array}$ \\
\end{tabular}

district hospital and, due to respiratory deterioration, subsequent intubation was needed. High-dose corticosteroid therapy was initiated to overcome acute organ rejection. As respiratory insufficiency further deteriorated, she was finally transferred to the intensive care unit of the medical department at the University Medical Center Freiburg.

Nasotracheal secretion was positive for viral influenza A/H1N1 RNA, proved by RT-PCR. Under the working diagnosis of influenza A/H1N1 pneumonia with bacterial superinfection, therapy with meropenem, clarithromycin and oseltamivir was initiated. Because a mutation causing resistance against Oseltamivir was detected.in further PCR work-up, oseltamivir was subsequently switched to zanamivir. Immunosuppressive therapy was continued with prednisolone and mycophenolate-mofetil, while tacrolimus was interrupted due to high serum levels.

Because of acute renal failure and suspected heparininduced thrombocytopenia type II, continuous venousvenous hemofiltration was initiated. Despite extracorporeal interventional lung assist implantation, sufficient carbon dioxide elimination could not be reached and the patient died due to rapidly progressive respiratory failure four days after the diagnosis of influenza A/H1N1 infection of the lung (timeline of the clinical course see Table 1).

\section{Bronchoscopy}

After admission to the medical intensive care unit, bronchoscopy was performed to evaluate initial differential diagnoses of acute graft rejection and infectious pneumonia. Bronchial mucosa was edematous and reddened. Mucus was viscous but not extensive in amount. Surgical anastomoses were inconspicuous. No pus or signs of acute bacterial infection could be observed. Bronchio-

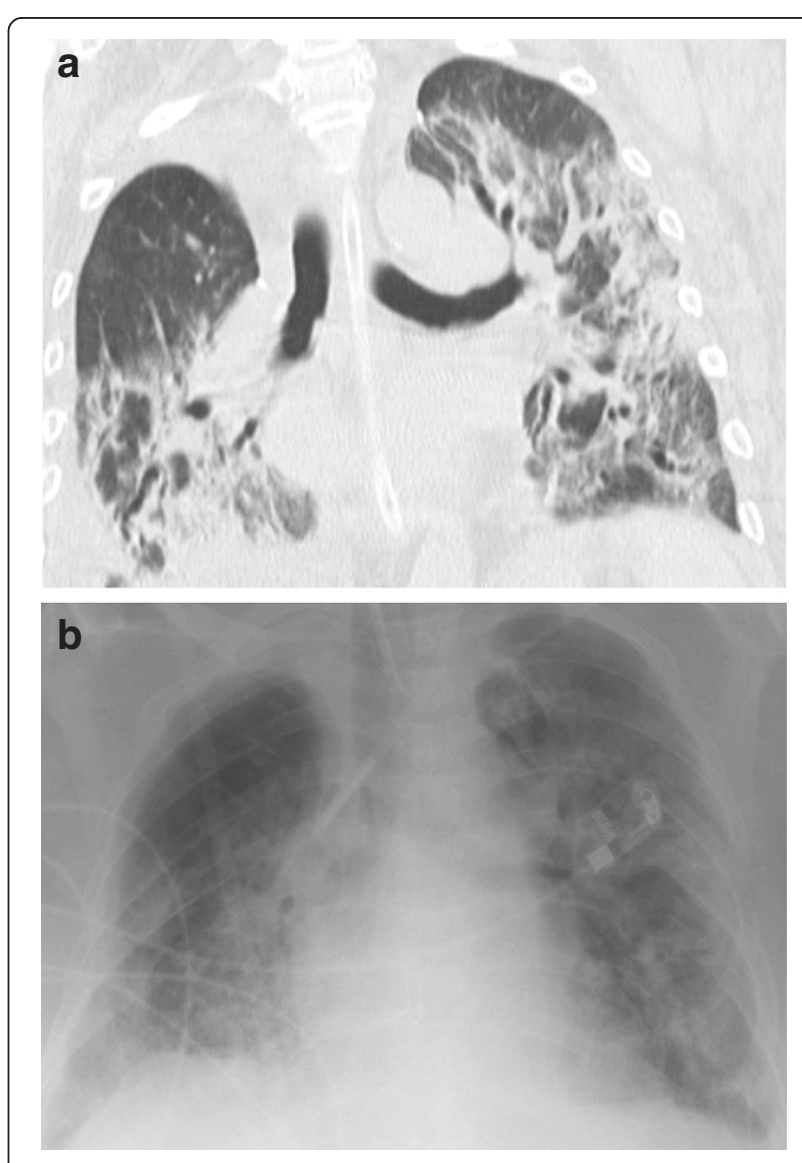

Figure 1 Radiographic findings: computer tomography shows bronchiectasis and consolidation especially in the right lower lobe (a) and increasing bilateral diffuse pulmonary infiltrates in both lungs with ground glass opacities seen in chest $x$-ray (b). 
alveolar lavage (BAL) fluid and sputum were sent to microbiological examination.

\section{Imaging}

Chest radiography revealed increasing bilateral diffuse pulmonary infiltrates in both lungs with ground glass opacities. Additionally, bronchiectasis and consolidation in the right lower lobe were noticed (Figure 1).

\section{Infectious workup}

In sputum and BAL samples, infection with influenza virus $\mathrm{A} / \mathrm{H} 1 \mathrm{~N} 1$ could be verified four days prior to death by real-time RT-PCR [1]. Multiplex-PCR proved to be negative for other bacterial or viral infections. Accordingly, cytomegalovirus PCR, cell culture assays and bacterial and fungal cultures were negative during her last hospitalisation period at the University Medical Center Freiburg.

\section{Post mortem}

Thoracic situs with status post double sided lung transplantation was evident with sufficient anastomoses of the transplanted organs. The lungs were consolidated in consistency but patchy discolorization typical for bacterial pneumonic infections were not present. Especially the lower parts of the lungs showed classical microscopic features of AFOP with distinct patchy intraalveolar formation of fibrin balls, focal fibroblast foci and diffuse organizing pneumonia (Figure 2). Hyaline membranes were not detected in any histological specimens. Thus, pure AFOP not associated with other histological patterns of DAD was verified. No signs of graft rejection, bacterial or fungal superinfections or a relapse of UIP were seen.

Molecular analysis of lung tissue revealed positive results for influenza A/H1N1by PCR. There was no detection of any bacterial or fungal infection in any analysed lung specimen, neither by microbiological nor by histological examination.

\section{Discussion}

Epidemic influenza $\mathrm{A} / \mathrm{H} 1 \mathrm{~N} 1$ originally developed in the United States of America and Mexico in 2009 and finally spread worldwide to a pandemic disease [2,3]. The first case in Germany was registered in April 2009 [4]. Influenza virus infections may cause serious pulmonary complications with death rates of approximately $7 \%[5,6]$. Although previously healthy patients may suffer from severe H1N1

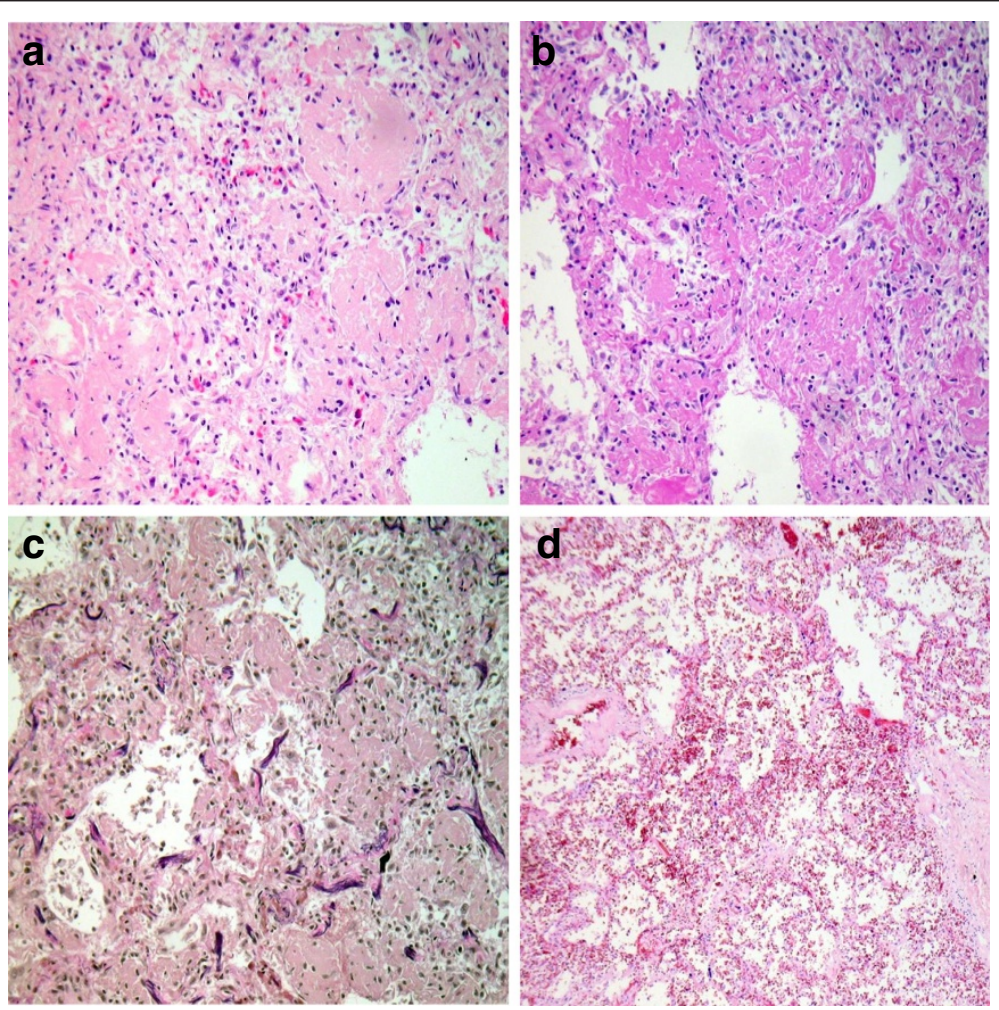

Figure 2 Postmortem histological findings in the lungs. a-c) AFOP: patchy involvment of lung parenchyma of the lower lobe with cubic intraalveolar fibrin deposits (so called fibrin balls) and formation of fresh fibroblast foci as sing for organizing pneumonia, hyaline membranes are absent (10x; H\&E, PAS and EvG staining); d) unaffected lung parenchyma of the upper lobe (10x; H\&E staining). 
infection, mortality proved to be particularly high in patients with predisposing conditions, i.e. obesity, pulmonary diseases, other than asthma or chronic obstructive pulmonary disease, pregnancy or pneumonia [6].

Patients with primary or secondary immunodeficiencies, particularly patients after lung transplantation are at especially high risk for development of severe pulmonary complications caused by influenza A/H1N1 infections. This, therefore, demonstrates a severe condition in lung transplanted patients $[2,5,7]$.

AFOP was first described by Beasley et al. [8] in 2002 and represents a distinct histological pattern of lung injury related to DAD. Beasley described two forms of AFOP: one less aggressive with good response to corticosteroids, the other with poor clinical outcome and a high mortality rate of $53 \%$ [8]. AFOP presents with specific histological features, i.e. patchy intraalveolar fibrin deposits, diffuse organizing pneumonia and absence of hyaline membranes. In the current literature, causes of AFOP are idiopathic or in combination with collagen vascular diseases [9], bacterial infections [10] and after certain drug exposure (e.g. amiodarone, abacavir [8,11], statins [12] as well as exposure to inhalative agents (e.g. coal mining, construction, zoological work, hairspray) [8].

One of a newborn child is reported with acute respiratory distress syndrome and AFOP after respiratory syncytial virus pneumonitis [13]. However, histology revealed hyaline membranes in the vicinity of AFOP-patterns, thus classifying it as DAD with focal patterns of AFOP. In contrast, upon autopsy of our patient no hyaline membranes were detected in any tissue sample. Therefore, in the case presented here, pure AFOP in association with viral infection is to be diagnosed.

\section{Conclusion}

Concluding, for the first time proof is given that viral agents at least of the myxovirus family - here influenza $\mathrm{A} / \mathrm{H} 1 \mathrm{~N} 1$ - can induce pure often fatal AFOP. Consequently, AFOP in the setting of viral pneumonia must be taken into account especially in immunocompromised patients as successful treatment with a combination of corticosteroids and mycophenolate-mofetil has recently been reported [14].

\section{Consent}

Informed and written consent for post-mortem investigation, scientific research and following publication as clinical image was given by the patient prior to death.

\section{Competing interests}

The authors declare that no competing interests exist.

\section{Authors' contributions}

CO, GK: autopsy workup, preparation of the manuscript. DH: virological investigations, preparation of the manuscript. LK: radiological evaluation, preparation of the manuscript. $\mathrm{CB}, \mathrm{AH}, \mathrm{SR}$, TP: clinical care, provision of clinical data, proof reading. MW: Histological evaluation, methodological support, proof reading. All authors read and approved the final manuscript.

\section{Acknowledgements}

The article processing charge was funded by the German Research Foundation (DFG) and the Albert Ludwigs University Freiburg in the funding program Open Access Publishing.

\section{Author details}

${ }^{1}$ Institute of Pathology, University Medical Center Freiburg, Breisacher Strasse 115a, D-79106, Freiburg, Germany. ${ }^{2}$ Department of Virology, University Medical Center Freiburg, Hermann-Herder Strasse 11, D-79104, Freiburg, Germany. ${ }^{3}$ Department of Radiology, University Medical Center Freiburg, Hugstetter Strasse 55, D-79106, Freiburg, Germany. ${ }^{4}$ Department of Pneumology, University Medical Center Freiburg, Hugstetter Strasse 55, D-79106, Freiburg, Germany. ${ }^{5}$ Department of Cardiovascular Surgery, University Medical Center Freiburg, Hugstetter Strasse 55, D-79106, Freiburg, Germany. ${ }^{6}$ Department of Thoracic Surgery, University Medical Center Freiburg, Hugstetter Strasse 55, D-79106, Freiburg, Germany. ${ }^{7}$ Department of Internal Medicine, University Medical Center Freiburg, Hugstetter Strasse 55, D-79106, Freiburg, Germany.

Received: 8 August 2012 Accepted: 8 May 2013

Published: 19 May 2013

\section{References}

1. Panning M, Baumgarte S, Laue T, Bierbaum S, Raith S, Drexler JF, Helmer A, Falcone-Kapper V, Kochs G, Campe H, et al: Singleplex real-time RT-PCR for detection of influenza $A$ virus and simultaneous differentiation of A/H1N1v and evaluation of the RealStar influenza kit. J Clin Virol 2011, 50(2):171-174

2. Danziger-Isakov LA, Husain S, Mooney ML, Hannan MM: The novel 2009 H1N1 influenza virus pandemic: unique considerations for programs in cardiothoracic transplantation. J Heart Lung Transplant 2009, 28(12):1341-1347

3. Wang $X$, Yang $P$, Seale $H$, Zhang $Y$, Deng $Y$, Pang $X$, He X, Wang Q: Estimates of the true number of cases of pandemic (H1N1) 2009, Beijing, China. Emerg Infect Dis 2010, 16(11):1786-1788.

4. Poggensee G, Gilsdorf A, Buda S, Eckmanns T, Claus H, Altmann D, Krause G, Haas W: The first wave of pandemic influenza (H1N1) 2009 in Germany: from initiation to acceleration. BMC Infect Dis 2010, 10:155.

5. Delaney JW, Fowler RA: 2009 influenza A (H1N1): a clinical review. Hosp Pract 2010, 38(2):74-81.

6. Nguyen-Van-Tam JS, Openshaw PJ, Hashim A, Gadd EM, Lim WS, Semple MG, Read RC, Taylor BL, Brett SJ, McMenamin J, et al: Risk factors for hospitalisation and poor outcome with pandemic A/H1N1 influenza: United Kingdom first wave (May-September 2009). Thorax 2010, 65(7):645-651.

7. Girard MP, Tam JS, Assossou OM, Kieny MP: The 2009 A (H1N1) influenza virus pandemic: a review. Vaccine 2010, 28(31):4895-4902.

8. Beasley MB, Franks TJ, Galvin JR, Gochuico B, Travis WD: Acute fibrinous and organizing pneumonia: a histological pattern of lung injury and possible variant of diffuse alveolar damage. Arch Pathol Lab Med 2002, 126(9):1064-1070.

9. Hariri LP, Unizony S, Stone J, Mino-Kenudson M, Sharma A, Matsubara O, Mark EJ: Acute fibrinous and organizing pneumonia in systemic lupus erythematosus: a case report and review of the literature. Pathol Int 2010, 60(11):755-759.

10. Heo JY, Song JY, Noh JY, Yong HS, Cheong HJ, Kim WJ: Acute fibrinous and organizing pneumonia in a patient with HIV infection and Pneumocystis jiroveci pneumonia. Respirology (Carlton, Vic 2010, 15(8): 1259-1261.

11. Lee SM, Park JJ, Sung SH, Kim Y, Lee KE, Mun YC, Lee SN, Seong CM: Acute fibrinous and organizing pneumonia following hematopoietic stem cell transplantation. Korean J Intern Med 2009, 24(2):156-159.

12. Spiro SG, Silvestri GA, Aqusti A: Clinical Respiratory Medicine. 4th edition. Philadelphia: Elsevir Saunders; 2012 
13. Cincotta DR, Sebire NJ, Lim E, Peters MJ: Fatal acute fibrinous and organizing pneumonia in an infant: the histopathologic variability of acute respiratory distress syndrome. Pediatr Crit Care Med 2007, 8(4):378-382.

14. Bhatti S, Hakeem A, Torrealba J, McMahon JP, Meyer KC: Severe acute fibrinous and organizing pneumonia (AFOP) causing ventilatory failure: successful treatment with mycophenolate mofetil and corticosteroids. Respir Med 2009, 103(11):1764-1767.

doi:10.1186/1471-2466-13-30

Cite this article as: Otto et al: Acute fibrinous and organizing

pneumonia associated with influenza $\mathrm{A} / \mathrm{H} 1 \mathrm{~N} 1$ pneumonia after lung

transplantation. BMC Pulmonary Medicine 2013 13:30.

\section{Submit your next manuscript to BioMed Central and take full advantage of:}

- Convenient online submission

- Thorough peer review

- No space constraints or color figure charges

- Immediate publication on acceptance

- Inclusion in PubMed, CAS, Scopus and Google Scholar

- Research which is freely available for redistribution 